\title{
ICE-CORE EVIDENCE FOR WEDDELL SEA ICE EXTENT DURING THE PAST 200 YEARS
}

\author{
(Abstract) \\ by \\ R. Mulvaney, A.P. Reid and D.A. Peel \\ Madingley Road, Cambridge CB3 OET, U.K.)
}

(British Antarctic Survey, Natural Environment Research Council, High Cross,

A continuous, detailed, 200-years record of the anionic species, chloride, nitrate and sulphate, has been measured on an ice core from Dolleman Island $\left(70^{\circ} 35.2^{\prime} \mathrm{S}, 60^{\circ} 55.5^{\prime} \mathrm{W}\right)$, Antarctic Peninsula. The site lies on the east coast of the Peninsula, and the chemistry of the core is dominated by the changing pattern of sea-ice distribution and storm activity in the Weddell Sea. Strong annual cycles in chloride and non sea salt sulphate reflect the dominance of the seasonal cycle in sea-ice distribution in the Weddell Sea, observed in time series derived from satellite imagery since the early 1970s. However, in the case of chloride there is also an exceptionally strong interannual variability, which in many parts of the core dominates the seasonal cycle.

Secular variations in the sea-ice extent appear to have a strong influence on the climate of the region and may play a major role in determining how long-term climate change in the Antarctic Peninsula relates to global climate change. The paper examines documented evidence for sea-ice extent in the Weddell Sea sector, and evaluates the usefulness of ice-core data for reconstructing this parameter in the earlier period.

\section{LATE PLEISTOCENE GLACIER DYNAMICS AND PALEOCLIMATE OF SOUTH-WESTERN MONTANA AND NORTH-EASTERN IDAHO, U.S.A. \\ (Abstract)}

by

Donald R. Murray*

(Department of Earth Sciences, Montana State University, Bozeman, MT 59717, U.S.A.)

Reliable reconstructions of paleoglaciers using topographic maps and aerial photographs allow calculation of effective basal shear stresses along the longitudinal profiles of these glaciers. Glacial flow theory applied to these shear stresses provides an estimate of the component of mass flux due to internal deformation. Assuming basal slip to be zero at the point where deformation mass flux is a maximum, minimum average accumulation gradients (above the equilibrium-line altitude (ELA)) and ablation gradients (below the ELA) can be calculated and minimum mass flux at the ELA can be estimated using the continuity equation. Average net winter accumulation can also be calculated by dividing the mass flux at the ELA by the accumulation area. Because local climate controls the mass balance of a glacier, and therefore the accumulation and ablation gradients, this model provides information on the climatic setting of these paleoglaciers.

*Present address: Department of Meteorology, Lyndon State College, Lyndonville, VT 05851, U.S.A.
This model also allows estimation of basal slip as a factor in point estimates of glacial flow. Application of the continuity model above and below the ELA generates additional estimates of mass flux at discrete points along the glacier. The difference between deformation mass flux and continuity flux at these points yields a first approximation of basal slip, which is highly variable along the glacier.

The model was tested on the Big Timber glacier of west-central Montana and applied to several other late Pleistocene glaciers in the northern Rocky Mountains of south-western Montana and north-eastern Idaho. Low ablation gradients $\left(<4.0 \mathrm{~mm} \mathrm{~m}^{-1}\right)$ suggest a climate during the late Pleistocene comparable to the present-day climate of the Brooks Range in Alaska. Calculated average net winter accumulation for the area is well below modern values, again indicating that the climate was much drier during the full glacial period. Basal sliding accounts for most (>90\%) of the glacial flow near the terminus of each glacier but is variable along the rest of the glacier. While the massbalance values are minima, they are assumed to be reasonable approximations of the actual values unless very high basal slip rates occurred along the entire length of each glacier. 